\title{
Práticas pedagógicas usuais do enfermeiro docente para superação do modelo tradicional de ensino
}

\author{
The usual pedagogical practices of the nurse teacher to overcome the traditional teaching \\ model
}

Prácticas pedagógicas usuales del enfermero profesor para superar el modelo tradicional de enseñanza

Francisco Lucas de Lima Fontes ${ }^{1 *}$, Rosane da Silva Santana ${ }^{2}$, José Gilvam Araújo Lima Junior ${ }^{3}$, Josélia Costa Soares ${ }^{1}$, Márcia Sandra Rêgo de Sousa ${ }^{4}$, llana Maria Brasil do Espírito Santo4, Janária Oliveira Figueiredo ${ }^{1}$, Karine do Nascimento Miranda Martins Granjeiro ${ }^{5}$, Laurice da Silva Nascimento ${ }^{1}$, Míriam Cláudia Fausto de Sousa Maroja ${ }^{6}$, Edilene Kalyne Bezerra de Sousa ${ }^{7}$, Marlúcia de Sousa Rodrigues ${ }^{1}$, Cynthia Soares de Araújo ${ }^{1}$, Shirlane da Silva Barbosa ${ }^{7}$, Mônika Cristina de Oliveira ${ }^{1}$.

\section{RESUMO}

Objetivo: Analisar as práticas pedagógicas usualmente empregadas pelo enfermeiro docente para superação do modelo tradicional de ensino. Métodos: Trata-se de um estudo descritivo com abordagem qualitativa, desenvolvido em uma universidade pública federal do município de Teresina-PI. Os sujeitos da pesquisa foram 12 enfermeiros docentes lotados em disciplinas teóricas. Os dados foram coletados por meio de entrevista semiestruturada entre os meses de fevereiro a abril de 2018, após aprovação do Comitê de Ética em Pesquisa. Resultados: Ao analisar os discursos dos entrevistados, identificou-se a interrupção com os recursos utilizados no modelo de ensino tradicional. Parte das falas evidenciou a busca pelo diálogo durante as aulas como forma de interação aluno-professor, o emprego de metodologias estimulantes à reflexão crítica dos conteúdos e a organização e planejamento das ações implementadas em sala de aula. Conclusão: Constata-se por meio dos discursos a suplantação do modelo de ensino tradicional, com adoção de recursos que constroem um ensino ativo e facilita o desenvolvimento das práticas pedagógicas pelo enfermeiro.

Palavras-chave: Prática do docente de enfermagem, Ensino de enfermagem, Docentes de enfermagem, ensino superior.

\section{ABSTRACT}

Objective: To analyze the pedagogical practices usually employed by the teaching nurse to overcome the traditional teaching model. Methods: This is a descriptive study with a qualitative approach, developed at a federal public university in the city of Teresina-PI. The subjects of the research were 12 teaching nurses full of theoretical subjects. Data were collected through a semistructured interview between February and April 2018, after authorization from the Research Ethics Committee. Results: After analyzing the speeches of the interviewees, the interruption with the resources used in the traditional teaching model was identified. Part of

${ }^{1}$ Faculdade UNINASSAU - Campus Redenção. Teresina, Piauí, Brasil. *E-mail: lucasfontesenf@hotmail.com 2Universidade Federal do Ceará. Fortaleza, Ceará, Brasil.

${ }^{3}$ Faculdade UNINASSAU. Parnaíba, Piauí, Brasil.

${ }^{4}$ Centro Universitário UNINOVAFAPI. Teresina, Piauí, Brasil.

${ }^{5}$ Universidade do Rio Grande. Rio de Janeiro, Rio de Janeiro, Brasil.

${ }^{6}$ Faculdade UNINASSAU. Belém, Pará, Brasil.

${ }^{7}$ Associação de Ensino Superior do Piauí. Teresina, Piauí, Brasil.

SUBMETIDO EM: 2/2019 
the speeches evidenced the search for dialogue during the classes as a form of student-teacher interaction, the use of stimulating methodologies to the critical reflection of the contents and the organization and planning of the actions implemented in the classroom. Conclusion: It can be seen through the speeches the supplanting of the traditional teaching model, with the use of resources that build active teaching and facilitates the development of pedagogical practices by the nurse.

Keywords: Nursing faculty practice, Education nursing, Faculty nursing, Education higher.

\section{RESUMEN}

Objetivo: Analizar las prácticas pedagógicas usualmente empleadas por el enfermero docente para superar el modelo tradicional de enseñanza. Métodos: Se trata de un estudio descriptivo con abordaje cualitativo, desarrollado en una universidad pública federal del municipio de Teresina-PI. Los sujetos de la investigación fueron 12 enfermeros docentes abarrotados en disciplinas teóricas. Los datos fueron recolectados por medio de una entrevista semiestructurada entre los meses de febrero a abril de 2018, tras la aprobación del Comité de Ética en Investigación. Resultados: Al analizar los discursos de los entrevistados, se identificó la interrupción con los recursos utilizados en el modelo de enseñanza tradicional. Una parte de las conversaciones evidenció la búsqueda por el diálogo durante las clases como forma de interacción alumnoprofesor, el empleo de metodologías estimulantes a la reflexión crítica de los contenidos y la organización y planificación de las acciones implementadas en el aula. Conclusión: Se constata por medio de los discursos la suplantación del modelo de enseñanza tradicional, con adopción de recursos que construyen una enseñanza activa y facilita el desarrollo de las prácticas pedagógicas por el enfermero.

Palabras-clave: Práctica del docente de enfermería, Educacíon en enfermaría, Docentes de enfermería, Educación superior.

\section{INTRODUÇÃO}

O enfermeiro, profissional bacharel, possui um grande desafio em sua formação, traz consigo um ensino primordialmente técnico ligado à assistência, seu foco de atuação. É dada, durante seu preparo profissional, uma atenção maior a características tecnicistas, sem preocupação com aspectos ligados a questões didáticopedagógicas e afins (PINHO MJS e NASCIMENTO ATP, 2017).

Diversos profissionais iniciam-se na docência, e apenas quando estão em sala de aula reconhecem a necessidade de apropriarem-se dos saberes docentes e das práticas pedagógicas. É fundamental que o enfermeiro se reconheça como docente e utilize de conhecimentos da área educacional para a melhoria do ensino-aprendizagem (BARBOSA ES et al., 2016).

A formação e os saberes pedagógicos de docentes bacharéis para atuação na docência do ensino superior têm sido tema de debate nas últimas décadas. A discussão surge devido ausência de preparo pedagógico para exercício da docência no ensino superior, que acaba por repercutir nas práticas docentes e pedagógicas desses profissionais em sala de aula (BARROS CMP e DIAS AMI, 2016).

Sacristán JG (1998) conceitua a prática pedagógica como uma manifestação dos hábitos escolares, correspondendo a um grupo de princípios, normas e atitudes relativas à transmissão reflexiva de conhecimentos e condutas acadêmicas. Esta prática pedagógica expõe comportamentos, crenças, maneiras de compreensão sobre a responsabilidade docente e valores comuns ao magistério, sendo que alguns destes aspectos requer maiores esclarecimentos.

Para Franco MS (2016), a prática pedagógica assume-se como práxis, quando apresenta um ato consciente e participativo, sendo resultado da multidimensionalidade que envolve o ato de educar. É importante que o professor esteja atento às necessidades dos alunos, desenvolvendo planos de trabalho que os incentivem a fazer parte do processo de ensino-aprendizagem. 
Discutir a prática pedagógica do enfermeiro docente oportuniza compreender como o mesmo percebe sua inserção e relevância no ensino superior. As perspectivas contemporâneas para o ensino e a aprendizagem na Enfermagem relacionam-se sob a ótica interdisciplinar dialógica com outras áreas de conhecimento, o que exige alterações constantes na forma de ensinar a Enfermagem e, assim, refletir sobre as mudanças necessárias na formação do enfermeiro para atuação deste no ensino superior (BRAGA MJG e VILLAS BÔAS $L$, 2014). Diante do que foi explanado, o objetivo do presente estudo foi analisar as práticas pedagógicas usualmente empregadas pelo enfermeiro docente para superação do modelo tradicional de ensino.

\section{MÉTODOS}

Estudo qualitativo descritivo realizado em uma instituição de ensino superior pública federal de Teresina, capital do Piauí. A coleta de dados ocorreu no Departamento de Enfermagem da instituição nos meses de fevereiro a abril de 2018. A predileção por esta academia deu-se pela oferta do curso de Enfermagem há mais de 40 anos no município.

Participaram do estudo 12 enfermeiros docentes responsáveis por disciplinas teóricas que desenvolviam suas funções em sala de aula. Foram incluídos apenas os profissionais que ministravam disciplinas teóricas com mínimo de três anos em sala de aula; e excluídos os que desempenhavam suas funções unicamente em campos de prática. Utilizou-se um roteiro de entrevista semiestruturado para a coleta dos dados, composto de dois segmentos: o primeiro, com informações pessoais e profissionais para caracterizar o perfil do grupo entrevistado, e o segundo, concebido de questões abertas sobre o tema, com vistas ao alcance do objetivo proposto.

As entrevistas foram programadas com os participantes e ocorreram dentro da instituição de ensino, em ambiente reservado. Os que aceitaram participar da pesquisa assinaram o Termo de Consentimento Livre e Esclarecido (TCLE). Os depoimentos foram gravados com recurso de um aparelho gravador de voz, como forma de assegurar a autenticidade das falas e percepções para posteriormente serem transcritas na íntegra.

O critério para encerramento das entrevistas ocorreu pelo mecanismo de saturação das falas, quando as narrativas, pensamentos e sentidos conferido pelos depoentes passa a ter constância, não contribuindo para novas categorias analíticas (MINAYO MCS, 2014).

De maneira a conferir segurança, sigilo e anonimato aos entrevistados, utilizou-se o pseudônimo DOC (de docente) em letras maiúsculas, seguido da numeração arábica de 01 a 12, estabelecida de acordo com a sequência de execução das entrevistas, assegurando não identificação a todos os participantes.

Aplicou-se a técnica de "Análise de Conteúdo" de Bardin (2016) sobre as falas dos entrevistados. Esse recurso possibilita organização sistemática dos dados coletados. Após transcrição, os discursos foram organizados de acordo com a similaridade de conteúdos para posteriormente ser iniciada a discussão.

Oriundo de um projeto de pesquisa intitulado "Percepções de enfermeiros docentes sobre as práticas pedagógicas em uma instituição pública de ensino superior em Teresina-Pl", emergiu-se três artigos científicos com metodologia equivalente, mas objetivos distintos que tratam: das estratégias de ensino utilizadas pelo enfermeiro docente; práticas pedagógicas utilizadas pelo enfermeiro para superação do modelo de ensino tradicional (presente estudo); e desafios encontrados pelo enfermeiro para o exercício da docência no ensino superior. O projeto passou por rigorosa análise do Comitê de Ética em Pesquisa da Faculdade de Ciências e Tecnologia do Maranhão (FACEMA) nº CAAE 82103318.7.0000.8007 até ter consequente parecer de aprovação № 2.492.663.

\section{RESULTADOS E DISCUSSÃO}

Participaram da pesquisa 12 enfermeiros docentes, dos quais $92 \%$ eram do gênero feminino, com predominância da faixa etária acima de 50 anos (42\%). Destacaram-se enfermeiros docentes com tempo de formação de mais de 30 anos (42\%). Da amostra, 100\% possuía mestrado como pós-graduação stricto sensu 
e $92 \%$ detinham o título de doutor. Dos professores, $25 \%$ atuava como docente do ensino superior há mais de 30 anos, $17 \%$, mais de 20 anos, 50\%, mais de 10 anos e $8 \%$, menos de uma década. Dos professores entrevistados, além de ministrarem aula na graduação, $67 \%$ eram docentes no curso de especialização. 0 regime de trabalho por dedicação exclusiva com 40 horas semanais esteve presente em $100 \%$ do perfil. Ao serem questionados se já haviam participado de algum curso que envolvesse a formação docente, $92 \%$ dos professores afirmaram que sim (Tabela 1).

Tabela 1 - Caracterização do perfil do grupo entrevistado.

\begin{tabular}{lc}
\hline \multicolumn{1}{c}{ Características } & $\%$ \\
\hline Gênero & $8 \%$ \\
\hline Masculino & $92 \%$ \\
Feminino & 0 \\
\hline Faixa etária & $33 \%$ \\
\hline 21 a 30 anos & $25 \%$ \\
31 a 40 anos & $42 \%$ \\
41 a 50 anos & \\
Acima de 50 anos & $8 \%$ \\
\hline Tempo de formação & $33 \%$ \\
\hline Menos de 10 anos & $17 \%$ \\
10 anos ou mais & $42 \%$ \\
20 anos ou mais & $100 \%$ \\
30 anos ou mais & $100 \%$ \\
\hline Pós-graduação concluída & $92 \%$ \\
\hline Especialização & $33 \%$ \\
\hline Mestrado & $8 \%$ \\
Doutorado & $50 \%$ \\
Pós-doutorado & $17 \%$ \\
\hline Tempo de atuação no ensino & $25 \%$ \\
\hline Menos de 10 anos & \\
\hline 10 anos ou mais & $100 \%$ \\
20 anos ou mais & $67 \%$ \\
30 anos ou mais & $58 \%$ \\
\hline Campo de atuação no ensino & $50 \%$ \\
\hline Graduação & $100 \%$ \\
\hline Especialização & 0 \\
\hline Mestrado & \\
Doutorado & \\
\hline Dedicação exclusiva no ensino & \\
\hline Sim & \\
Não & \\
\hline Participação em eventos de formação docente & \\
\hline Sim & \\
Não & \\
\hline Fonte: dados da pesquisa (2018). & \\
\hline
\end{tabular}

A maneira de construir as práticas de ensino, ocorre quando o professor percebe que ensinar é oferecer oportunidades para que o aluno assuma as próprias responsabilidades pelo seu aprendizado. Dessa forma, o planejamento e a organização das ações a serem implementadas em sala de aula colaboram para decisões que podem ser tomadas pelo docente durante o processo de ensino-aprendizagem, favorecendo a compreensão, estimulando novos saberes, permitindo ao discente envolvimento e construção de possibilidades para o aprendizado (MORETTI-PIRES RO et al., 2010).

Ao analisar os discursos dos entrevistados, identificou-se a interrupção com os recursos utilizados no modelo de ensino tradicional, baseado no professor como único detentor do conhecimento, sendo o aluno um 
"recipiente" a ser depositado todo o saber. Parte das falas evidenciou a busca pelo diálogo durante as aulas como forma de interação aluno-professor, o emprego de metodologias estimulantes à reflexão crítica dos conteúdos e a organização e planejamento das ações implementadas em sala de aula.

Nesse contexto, para formar um aluno e futuro profissional crítico-reflexivo, o próprio professor precisa ser crítico-reflexivo, refletir sobre a sua prática e despertar os sentidos do aluno para além da sala de aula (MADEIRA MZA e LIMA GSB, 2010), conforme explanado nas falas dos DOCs 01, 05 e 09.

“[...] desenvolvo minha prática pedagógica com responsabilidade, com consciência, buscando respeitar o aluno, sabendo que o aluno realmente precisa ter estímulo aqui pra desenvolver seu senso crítico [...]" - DOC 01

"[...] A gente tem uma história... um momento assim... das práticas muito voltadas apenas pra transmissão de conhecimento e depois a gente vai verificando mudanças [...] Ninguém é uma página em branco, você não pode imprimir conhecimentos num aluno [...] a gente precisa que 0 nosso aluno ele participe mais das aulas de forma mais ativa, não só professor colocando conhecimento pra eles..." - DOC 05

"[...] a gente constrói uma aula fundamentada tanto no diálogo, na exposição dialogal, como também na interação para que o aluno também possa dar sua contribuição, que o aluno possa ter um envolvimento." - DOC 09

Para construção do aluno crítico-reflexivo, é essencial uma atenção maior sobre a prática pedagógica, em que o professor exerce papel primordial: o de norteio. Pois o docente, contextualizando, é o sujeito de transformação, que "liga e religa" os conhecimentos, direciona aos conteúdos e estimula os alunos à aprendizagem ativa (BACKES DS et al., 2010).

A utilização de práticas pedagógicas ativas tem como objetivo incluir o aluno no processo de ensinoaprendizagem, instigando a análise, o questionamento e a discussão, deixando de lado o modelo tradicional de ensino, pautado na mera transmissão de conhecimentos, enciclopédico, tendo o professor como único detentor de todo o saber. Os depoentes expressaram por meio das narrativas, o emprego de recursos favoráveis ao ensino ativo, como constatado nos relatos dos DOCs 02, 03, 06 e 12.

"Eu utilizo todas as técnicas pedagógicas possíveis. Seminários, oficinas, exposição oral, trabalho de grupo, trabalho de pesquisa [...] aplicando práticas pedagógicas, a nota surge analisando a participação do aluno em sala de aula." - DOC 02

"A minha prática pedagógica, ela é desenvolvida, com base especificamente em foco na aprendizagem do aluno [...] Então a gente trabalha teoria e prática, então essa prática pedagógica ela envolve desde de aulas expositivas, seminários, aulas práticas em laboratório de simulação, em laboratório de habilidades práticas e aulas em campos de práticas nos serviços hospitalares." - DOC 03

"[...] a gente utiliza das seguintes formas: aulas expositivas, disso a gente não pode fugir, né? A gente trabalha muito também com textos, artigos científicos que a gente distribui pros alunos, divide em grupos e tenta fazer a dinâmica de estudos, seminários..." - DOC 06

"[...] aquela maneira que nós utilizávamos mais antigamente, mais expositiva, mais tradicional foi mudando essa prática e hoje a gente trabalha de uma maneira totalmente diferente de quando eu fui formada, por exemplo. Provas, pra você fazer uma avaliação eu não uso... As minhas avaliações são com consulta, por exemplo. Os alunos, eles trabalham individualmente, mas com consulta, internet, textos, o que ele quiser levar pra prova ele pode levar, né? Então assim, muita coisa mudou porque no meu entendimento não adianta você querer que o aluno decore aquela matéria pra ir se dar bem numa prova, quando eu faço prova objetiva eu faço uma prova mais bem elaborada pra ele pensar um pouco antes de responder, né?" - DOC 12 
Silva UB e Bruni AL (2017) apresentam as práticas pedagógicas como ativas ou passivas, caracterizando ambos os modelos de ensino e exemplificando as práticas usualmente adotadas (Quadro 1).

Quadro 1 - Práticas pedagógicas ativas e passivas

\begin{tabular}{|c|c|}
\hline ENSINO PASSIVO & ENSINO ATIVO \\
\hline \multicolumn{2}{|c|}{ CARACTERIZAÇÃO } \\
\hline $\begin{array}{l}\text { Assume o professor como centro das atenções, o } \\
\text { "conhecedor de todo o saber". Existe uma reduzida } \\
\text { participação do discente no processo de ensino que, } \\
\text { passivamente, deveria absorver ou memorizar o } \\
\text { conhecimento transmitido pelo professor. }\end{array}$ & $\begin{array}{l}\text { Assume que o conhecimento se constrói a partir de } \\
\text { uma série de atividades para o desenvolvimento de } \\
\text { estruturas organizadas de informações e construção } \\
\text { do saber. O aprendizado acontece a partir de } \\
\text { organização esquemas de ações estruturadas em } \\
\text { função das experiências vividas e do meio onde o } \\
\text { aluno vive. }\end{array}$ \\
\hline \multicolumn{2}{|c|}{ PRÁTICAS PEDAGÓGICAS UTILIZADAS } \\
\hline $\begin{array}{l}\text { Envolvem ações que levam os alunos a } \\
\text { memorização de conteúdo. Exemplos: aulas } \\
\text { puramente expositivas, sem feedback do aluno, } \\
\text { apostilas com conteúdo sintetizado, listas de } \\
\text { exercícios, livro texto, sem espaço para discussão, } \\
\text { com critérios objetivos de avaliação de desempenho } \\
\text { do aluno, como prova escrita, com questões de } \\
\text { múltipla escolha, que remeta o aluno a práticas de } \\
\text { memorização e reprodução de conteúdo sintetizados } \\
\text { pelo professor. }\end{array}$ & $\begin{array}{l}\text { Envolvem ações que levem os alunos a uma } \\
\text { participação mais intensa no processo de } \\
\text { aprendizagem. Exemplos: aulas expositivas } \\
\text { dialogadas; estudos dirigidos; aprendizagens } \\
\text { experienciais a partir de entrevistas com } \\
\text { profissionais no mercado, seminários com toda a } \\
\text { classe, mesa redonda, debates, com a participação } \\
\text { de todos os alunos, aprendizagem baseada em } \\
\text { problemas; ensino em pequenos grupos, ensino com } \\
\text { pesquisa; ensino à distância (como grupos de } \\
\text { discussão online); estudo de casos; ensino com } \\
\text { pesquisa; oficinas (laboratórios ou workshops); } \\
\text { escritórios, laboratórios ou empresas modelo; } \\
\text { simulações e jogos. }\end{array}$ \\
\hline
\end{tabular}

Fonte: Adaptado de Silva UB e Bruni AL (2017).

A organização e planejamento das ações implementadas em sala de aula foram outros pontos importantes narrados pelos docentes no pleno desenvolvimento das práticas pedagógicas.

"Em sempre faço planejamento antes de dar a aula, acho que isso faz parte de todas as aulas, né?" - DOC 08

"[...] Eu tento me organizar de uma forma que eu atenda aos objetivos que eu tenho na disciplina, pra atingir as competências mínimas para aquela disciplina e... eu também tento contemplar o número de alunos..." - DOC 11

As falas dos DOCs 08 e 11 demonstraram que, para o uso das práticas pedagógicas, é importante também planejar e organizar as atividades que devem ser implementadas em sala de aula. É nesta linha tênue que muitos confundem prática pedagógica com prática docente. A prática pedagógica tem relação direta com planejamento e administração das intervenções que serão feitas em sala de aula, enquanto que a prática docente se relaciona com as ações implementadas em sala de aula, na interação professor-aluno (TOZETTO SS e GOMES TS, 2009).

A prática pedagógica pode ser entendida como um fenômeno de natureza bem mais amplo, que engloba diretamente as práticas docentes em sala de aula. Imagine a prática pedagógica como um círculo grande e que, no interior deste círculo grande estivesse outro círculo, menor, a prática docente ou educativa (SACRISTÁN JG, 1999).

O docente precisa planejar suas ações baseando-se em uma pedagogia construtivista, ou seja, criando circunstâncias favoráveis ao aprendizado do aluno, administrando conflitos, conduzindo metodologias, sanando dificuldades da formação, trabalhando com condutas como prática docente reflexiva com estímulo à 
criticidade. Essas ações levam o educador, a uma prática pedagógica inovadora, negociável e norteadora, permitindo assim a construção de novos saberes (VALENTE GSC e VIANA LO, 2009).

Freire $\mathrm{P}$ e Shor I (2013) ressignificam a prática pedagógica como algo que não pode ser definido, mas sim concebido e transformado mediante os preceitos em que estiver fundamentada a ideia. Para os autores, a prática pedagógica surge como um mecanismo de diálogo, com a construção do conhecimento bidirecional realizada por ambos os atores ativos neste processo: docente e discente, nos rumos de uma leitura crítica da realidade.

As práticas pedagógicas são organizadas para executar determinadas ações ligadas às competências educacionais. São práticas lotadas de intencionalidade, tendo em vista que no próprio sentido da práxis caracteriza-se pelo estabelecimento de intenções, norteia e dá rumo à ação, requerendo uma intervenção planejada e científica sobre o objeto, objetivando a transformação da realidade social ao qual os atores, professor e aluno, estão inseridos. Tais práticas, por mais planejadas que sejam, são imprevisíveis, pois dependem da interação aluno-professor dentro da sala de aula (FRANCO MS, 2016).

Nem toda prática docente é uma prática pedagógica. A prática docente ajusta-se como prática pedagógica quando está incluída a intencionalidade prevista para sua ação. Desse modo, um professor que sabe o real propósito de sua aula ante a formação de seu aluno, que sabe como sua aula integra e expande a formação do discente, que compreende o significado de sua ação, possui uma atuação pedagógica singular: ele dialoga com as deficiências do aluno, não desiste da sua aprendizagem, acompanha seu empenho, produz 0 aprendizado e considera que este será relevante para o aluno (FRANCO MS, 2016).

Apesar de ter se observado na maioria dos discursos a busca pela superação do modelo tradicional e tecnicista de ensino, chama atenção para a fala de um dos docentes.

"Eu desenvolvo (a prática pedagógica) voltado muito pra questão prática, pra questão técnica, né? Eu tenho que focar que eu tô formando enfermeiro, não tô formando pesquisador, então eu preciso focar no princípio de atuação mesmo no serviço, na questão mais técnica..." - DOC 10

Durante a formação do enfermeiro na modalidade bacharelado fica a cargo do docente o papel de mediar o conhecimento de seu aluno e permitir ao mesmo, ainda na sua formação, o desenvolvimento de conhecimentos e habilidades intrínsecos ao campo primário de atuação nos serviços de saúde, isso se dá mediante saberes teórico-práticos adquiridos na vivência, o que facilita a construção do saber (RIBEIRO JF et al., 2018).

Ser bacharel professor traz também seus pontos positivos, como a possibilidade de compartilhamento com os discentes sobre as experiências vividas em seu campo de atuação, tendo em vista que, como profissionais que possuem vivência no mundo do trabalho, podem reproduzir suas atividades apoiados nos obstáculos e obrigações que surgem. O bacharel docente traz a vivência das práticas consigo para dentro da sala de aula e colabora para a formação de seus alunos, tendo a formação continuada como alternativa importante ao desenvolvimento de suas experiências (OLIVEIRA VS e SILVA RF, 2012).

Outro ponto citado pelos depoentes diz respeito a reciclagem de conhecimentos por meio de cursos, sejam cursos científicos de curta duração, sejam cursos na modalidade lato sensu e stricto sensu, como exposto pelos DOCs 04, 07 e 12.

"Então eu procurei fazer "Docência Superior", fiz um mestrado em Educação, participo de docência na saúde que eu já me especializei, fiz cursos à distância nessa área, pra gente poder estar no dia a dia da sala de aula aplicando coisas novas, inovadoras." - DOC 04

"É... a minha prática pedagógica eu sempre busco aperfeiçoamento, leituras, busca de inovação de conhecimento, dinâmicas no dia a dia para sempre estar sendo aperfeiçoada e claro sempre trazendo novidades, dinâmicas, novos aprendizados, publicações mais recentes que envolvam a temática abordada." - DOC 07

REAS/EJCH | Vol. Sup. 23 | e249 | DOI: https://doi.org/10.25248/reas.e249.2019 Página 7 de 9 


\begin{abstract}
"Além de ter feito mestrado, doutorado, pós-doutorado, o que me dá, vamos dizer assim... melhores condições para eu desenvolver a minha prática pedagógica, eu fiz um curso uma época aí que era um curso do Ministério da Saúde que era de formação pedagógica [...] em que fomos preparados pra trabalhar as mudanças com base nas novas diretrizes curriculares, quer dizer, as mudanças nos currículos, né?" - DOC 12
\end{abstract}

Apesar desses cursos oferecerem um preparo maior e melhores condições a quem deseja ser docente, Masseto MT (2012) pontua que, tanto o mestrado quanto o doutorado qualificam o profissional, prioritariamente, ao desenvolvimento de pesquisa, todavia isto sendo insuficiente para a formação docente no ensino superior. Para o autor, é relevante a implementação da formação pedagógica aos acadêmicos de pós-graduação.

Comumente, para as instituições de ensino, o elemento curricular vale pelo conteúdo exposto. Para lecionar, professores são escolhidos e contratados pelo domínio que demonstram ter sobre determinado conteúdo. Acata-se a ideia de que o indivíduo que sabe o conteúdo tem bagagem para transmiti-lo, como se o processo educativo se restringisse a simples transmissão passiva de conhecimento (CASTRO JÚNIOR R, 2012).

É relevante, portanto, que as instituições detentoras de programas de pós-graduação rearranjem suas grades curriculares com vistas a oferta de mais disciplinas que supram deficiências primárias na formação do bacharel, tendo em vista que as disciplinas ofertadas que se relacionam com a didática e metodologias do ensino superior, muitas vezes, possuem carga horária insatisfatória para despertar reflexão sobre o "ser professor universitário".

\title{
CONCLUSÃO
}

O curso de Enfermagem por si só, exige muita racionalidade técnica. Cabe ao enfermeiro, enquanto professor, a superação do modelo de ensino tradicional tecnicista, a fim de tornar o processo de formação do enfermeiro dinâmico, dialógico e crítico-reflexivo. As grades curriculares do curso ainda contemplam muito o modelo biomédico/assistencial, enquanto que outras áreas de atuação do enfermeiro, como o ensino, acabam ficando esquecidas durante a formação. Após conclusão do curso, o enfermeiro precisa qualificar-se e aperfeiçoar-se a fim de possuir o mínimo preparo pedagógico para assumir as salas de aula. Essa qualificação para a docência vai desde cursos que envolvam a formação docente até cursos na modalidade stricto sensu, obrigatórios para o exercício da docência no ensino superior.

Constata-se por meio dos discursos a suplantação do modelo de ensino tradicional, com adoção de recursos que constroem um ensino ativo e facilita o desenvolvimento das práticas pedagógicas pelo enfermeiro. Espera-se que este estudo contribua para melhorias nas práticas de ensino, oportunizando espaço para reflexão em professores e aspirantes à docência sobre este campo de atuação da Enfermagem, de modo a cooperar com a valorização do professor no ensino superior.

\section{AGRADECIMENTOS}

Os autores são gratos ao Departamento de Enfermagem da Universidade Federal do Piauí por autorizar a realização da pesquisa na referida instituição. Os autores agradecem ainda a todos aqueles enfermeiros docentes que deram suas contribuições, aceitando participar voluntariamente deste estudo.

\section{REFERÊNCIAS}

1. BACKES DS et al. Repensando o ser enfermeiro docente na perspectiva do pensamento complexo. Revista Brasileira de Enfermagem, 2010; 63(3): 421-426.

2. BARBOSA ES et al. O ser professor e o seu desenvolvimento profissional na perspectiva de enfermeiros que lecionam no ensino superior. Revista COCAR, 2016; 10(20): 274-295.

3. BARDIN L. Análise de conteúdo. 1ํㅡㄹ. ed., Edições 70, Brasil, 2016. 
4. BARROS CMP, DIAS AMI. A formação pedagógica de docentes bacharéis na educação superior: construindo o Estado da Questão. Revista Educação em Questão 2016; 54(40): 42-74.

5. CASTRO JÚNIOR R. Educação superior: a construção da praxis do bacharel docente. Revista Digital de Administração 2012; 2(2): 45-58.

6. FRANCO MS. Prática pedagógica e docência: um olhar a partir da epistemologia do conceito. Revista Brasileira de Estudos Pedagógicos, 2016; 97(247): 534-551.

7. FREIRE P, SHOR I. Medo e Ousadia: O Cotidiano do Professor. 13ae ed., Paz e Terra, São Paulo, 2013.

8. MADEIRA MZA, LIMA GSB. O significado da prática docente na constituição do Saber ensinar das professoras do curso de enfermagem da Universidade federal do Piauí. Texto \& Contexto Enfermagem, 2010; 19(1): 70-76.

9. MASETTO MT. Competência pedagógica do professor universitário. $2^{a}$ ed, Summus, São Paulo, 2012.

10. MINAYO MCS. O desafio do conhecimento: Pesquisa qualitativa em saúde. 14ª ed., Hucitec, São Paulo, 2014.

11. MORRETI-PIRES RO et al. Potencialidades da problematização freiriana no ensino "didática em enfermagem". Revista Cogitare Enfermagem, 2010; 2(15): 308-313.

12. OLIVEIRA VS, SILVA RF. Ser bacharel e professor: dilemas na formação de docentes para a educação profissional e ensino superior. Holos, 2012; 28(2): 193-205.

13. PINHO MJS, NASCIMENTO ATP. Identidade profissional de enfermeiros/as: perspectivas de formação docente. Revista Profissão Docente, 2017; 17(37): 78-87.

14. RIBEIRO JF et al. Prática pedagógica do enfermeiro na docência do ensino superior. Revista de Enfermagem UFPE, 2018; 12(2): 291-302.

15. SACRISTÁN JG. O Currículo: Uma reflexão sobre a prática. $3^{\underline{a}}$ ed. Porto Alegre: Artmed, 1998.

16. SACRISTÁN JG. Poderes instáveis em educação. 1ª ed. Porto Alegre: Artmed, 1999.

17. SILVA UB, BRUNI AL. O que me ensina a ensinar? Um estudo sobre fatores explicativos das práticas pedagógicas no ensino de Contabilidade. Revista de Educação e Pesquisa em Contabilidade, 2017; 11(2): 214-230.

18. TOZZETO SS, GOMES TS. A prática pedagógica na formação docente. Reflexão e Ação, 2009; 17(2): $181-196$.

19. VALENTE GSC, VIANA LO. Da formação por competências à prática docente reflexiva. Revista lberoamericana de Educación, 2009; 48(4): 1-7.

20. BRAGA MJG, VILLAS BÔAS L. Enfermagem e docência: uma reflexão sobre como se articulam os saberes do enfermeiro professor. Revista @mbienteeducação, 2014; 7(2): 256-267. 